\title{
Clinical and Histopathological Study of Sheep Pox in Ethiopia
}

\author{
Mersha Chanie \\ Department of Paraclinical Studies, Faculty of Veterinary Medicine, University of Gondar, P. O. Box: 196, \\ Gondar, Ethiopia
}

[Received: November 23, Accepted: December 26, 2011]

\begin{abstract}
Clinical signs, postmortem and histopathological lesions in sheep suffering from sheep pox were evaluated. Animals were selected purposively from Yemeze Gera Midir, Kalu and Kutaber district veterinary clinics, Ethiopia. Relevant data and samples were collected for the period from November, 2007 to December, 2009. Of the total 3263 sheep examined, 49.5\% (1615) showed skin lesions, suppressed appetite and depression. The lesions were detected in all ages and both sexes. The chief clinical signs observed were: fever, macules, papules, nodules, enlarged lymph nodes, dyspnea, conjunctivitis, nasal discharge and labored and noisy breathing. The mortality rate was $10.42 \%$ (340). At postmortem, the skin showed necrotic lesions and scabs surrounded by areas of edema, hemorrhage and congestion. The mucous membranes of the eyes, nose, mouth, vulva and prepuce were ulcerated. The lungs contained edematous, congested, consolidated areas, and firm gray to white nodules. Papules and ulcerated areas were common on the abomasal mucosa. The histopathologic examination of hematoxylin and eosin and van Gieson stained skin biopsy sections taken from 21 sheep were done in Sebeta National Veterinary Diagnostic Center. The degree of damage on the skin varied from minimal to severe. The reaction to the virus range from few epidermal hyperplasia to different degrees of degeneration and necrosis of epidermis and dermis.
\end{abstract}

Keywords: Clinical sign; Histopathology; Sheep pox; Skin biopsy.

\section{INTRODUCTION}

The profitability of sheep is often affected due to occurrence of diseases, especially the infectious diseases ${ }^{[16]}$. Among these infectious diseases affecting sheep, sheep pox is considered to be economically the most important in the tanning sector due to its slow and permanent scar formation [13]. Heavy economic losses in sheep pox outbreaks are due to mortality, abortions and loss of market value of the affected animals ${ }^{[12]}$.

Morbidity and mortality vary with the breed of the animal, its immunity to Capri pox viruses, and the strain of the viruses. It is an OIE list A disease. Pox infections can limit trade, export, and development of intensive livestock production. It also prevents the import of new breeds ${ }^{[12]}$. Mortality may be up to $50 \%$ in a fully susceptible flock and as high as $100 \%$ in young animals ${ }^{[7,12]}$. Mild infections are common in indigenous breeds. However, symptoms may be more severe in lambs, stressed animals, animals that have concurrent infections or animals that come from areas where pox has not occurred for sometime ${ }^{[5,9 \text {, }}$ 14].

Incubation period of the disease is 8 to 13 days following contact between an infected and susceptible animal. It may be as short as 4 days following experimental infection by intradermal inoculation or mechanical transmission by insects. Transmission of sheep pox among flocks and transfer between countries occur from the movement of sheep ${ }^{[6,12]}$. All age groups can be affected, however the disease is more severe in young animals than adults ${ }^{[7]}$. The systemic signs include fever (104$\left.107.60^{\circ} \mathrm{F}\right)$, conjunctivitis, rhinitis, lymphadenopathy, anorexia and depression $[2,3,8]$. The mucous membranes can become necrotic and animals may develop a mucopurulent nasal or ocular discharge ${ }^{[13]}$. In Ethiopia, Sheep pox is a serious problem and has been reported from different regions of the country ${ }^{[10,17]}$. Generally, sheep pox is a disease of considerable economic importance for Ethiopian sheep farming. However, little information is available regarding transmission and vaccination of naturally occurring sheep pox in extensive production systems. The present study analyses the clinical and histopathological findings of sheep pox in indigenous sheep in Ethiopia.

\section{MATERIALS AND METHODS}

\section{Experimental Animals}

The study was conducted in three districts of the northeastern Ethiopia (Yemenz Gera Midir, Kalu and Kutaber) from November 2007 to December 2009. Indigenous sheep managed under extensive management system were targeted as study animals. Sheep brought to veterinary clinics from the three districts were purposively selected.

Study methodology 
Questionnaire survey: Questionnaire was prepared regarding general information on livestock ownership, importance of sheep rearing, awareness on sheep pox and its effect on sheep production. Sixty sheep owners; 20 from each clinic were interviewed.

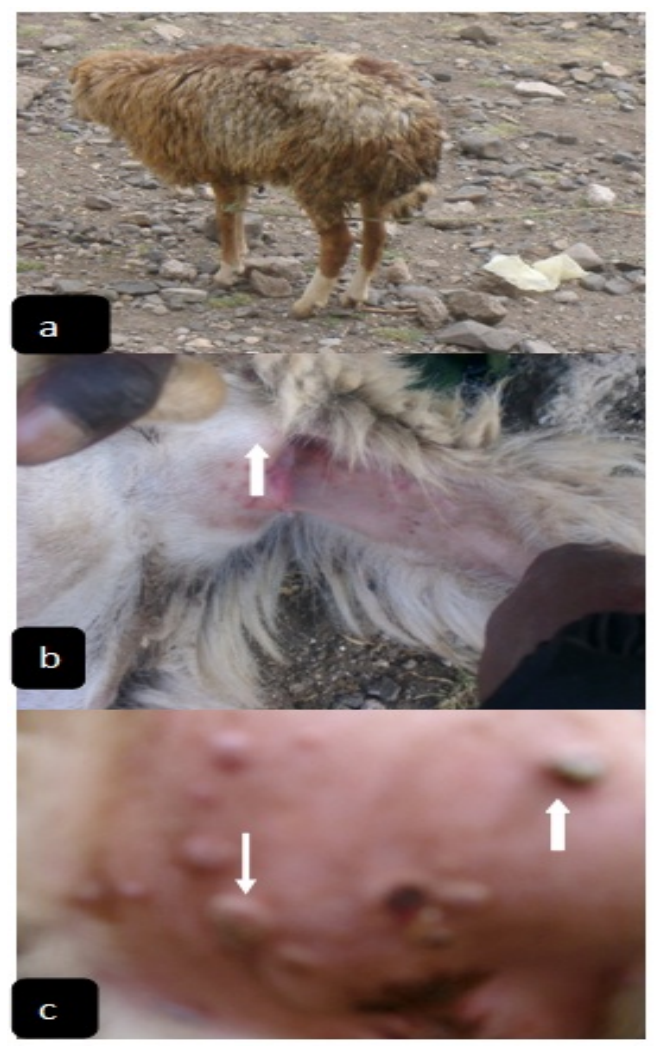

cleared in xylene, impregnated and embedded in paraffin. Tissue blocks were then sectioned at $4-5 \mu \mathrm{m}$ thickness, and sections were deparaffinized in xylene, hydrated in graded ethanol alcohol and stained with Haematoxylin and Eosin (Mayor's Haematoxylin Stain). Tissue sections were also

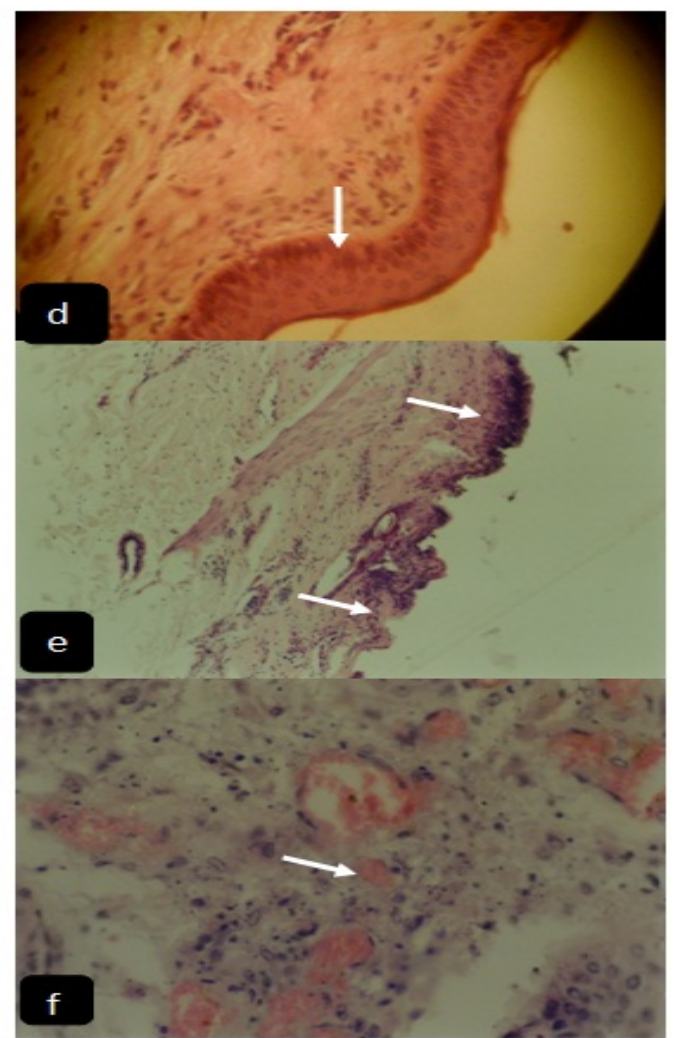

Figure 1. Sheep infected with sheep pox usually found depressed (a). Macroscopic skin lesions on infected sheep show erythematous macules (b), on progression the lesions is changed in to pustular form (c), in histopathological examination of skin sample there shows acanthosis in epidermis (d with magnification 100x), inflammatory cell infiltrations and necrosis of the epidermis (e 40x) and necrotic areas and cellular debris in the dermis ( $\mathrm{f}$ with magnification 400x).

Clinical examination: A total of 3263 sheep were conveniently selected and clinically examined. Physical examination of all parts of the body including the mucous membranes, mouth, the ears, perineum, less wool covered body parts and scrotal areas was carried out. Rectal temperature was also taken. Visual inspection and palpation of the skin were utilized to detect nodular lesions.

Skin samples: Skin samples for histopathology were collected from 21 sheep with characteristic sheep pox lesions. Samples from live animals were taken after inducing local anesthesia with lidocane $2 \%$ at biopsy sites, hairs were closely clipped and sites were disinfected with $70 \%$ alcohol. Then incisions were made via the skin, 4 X $4 \mathrm{~mm}$ skin biopsies were collected and fixed in $10 \%$ neutral buffered formalin for at least 24 hours before processing for histopathological examination ${ }^{[4] \text {. }}$

Preparation of skin biopsies for histopathology: Skin biopsies were dehydrated in graded ethanol alcohol, stained with van Gieson's staining method to determine the extent of proliferation of fibroblasts in the dermal layer of the skin ${ }^{[4]}$.

\section{Data management and analysis}

Microsoft excel were used for data management. Descriptive statistics such as percentage was used to summarize the proportion.

\section{RESULTS}

\section{Questionnaire survey}

The questionnaire survey indicated that sheep were among the most important animals reared by farmers for different purposes; $88 \%$ for sale and reserve, $75 \%$ for meat and $62 \%$ for skin. The respondents from Yemenze Gera Midir (90\%), Kalu (78\%) and Kutaber $(93 \%)$ reported the presence of sheep pox lesions on their animals. Among the total interviewed animal owners there was a total of $340(10.42 \%)$ lambs died due to sheep pox during the study period. 
This indicates the significance of the disease in sheep production in the study areas.

\section{Clinical observations}

Sheep which were clinically sick showed increased body temperature up to $104-108^{\circ} \mathrm{F}$ (Table 1) beginning four to five days post infection and then gradually subsiding to normal value about two weeks after infection. During this period, all the sheep infected were found depressed (figure 1a). During the acute phase of infection, nasal discharge accompanied by intense coughing, dyspnea, conjunctivitis and lacrimal discharge were observed. Inspection and palpation of sick animals showed characteristic full-thickness skin lesions and enlarged lymph nodes.

The commonest sites where lesions developed on the body included axilla, eyelids, inguinal areas (under tail), muzzle, ears and mucous membranes. In six of the sheep clinically examined (four from Yemenze Gera Midir and two from Kutaber district) generalized skin lesions were seen. Characteristic skin lesions were clearly observed in body parts with less wool coverage (perianal and face).

The nodules in heavy wool covered sites were detected by fleece parting and palpation. The superficial lymph nodes were found enlarged. But the prescapular lymph node was found extremely enlarged.

Skin lesions included erythematous macules (figure 1b) and papules, measured 2 to $6 \mathrm{~mm}$ in diameter which gradually became larger and nodular with typical circumferential demarcation. When the necrotic centers of the nodules were removed, the lesions appeared ulcerated. Pustular changes were observed during the progression of these lesions (figure 1c) Lesions in mouth, eyes and eyelids may be the cause for salivation, anorexia, rhinitis, conjunctivitis and blepharitis with mucopurulent discharge. Some of the individual skin lesions healed, leaving a typical "pock" mark on the skin.

\section{Necropsy examination}

At postmortem examination, the skin was found containing macules, papules, necrotic lesions and scabs, surrounded by areas of edema, haemorrhages and congestion. The papules were found across the epidermis, dermis and the musculatures. In a few cases, lungs were found congested, edematous, firm, grey in colour and containing few whitish areas. Lymph nodes throughout the body were mostly enlarged and edematous.

\section{Histopathological observations}

Epidermal changes included acanthosis (figure 1d), parakeratosis and hyperkeratosis with degeneration of proliferating epithelial cells. The dermis showed micro-vesicles of various sizes filled with pink fluid, vasculitis, infiltration of macrophages, fibroblasts and necrosis (figure 1e).
In some skin slides there was also granulation tissue formation and few other slides showed necrotic debris and pus formation (figure 1f). Pulmonary nodules were characterized by proliferative bronchiolitis and alveolitis, giving the appearance of gland-like structures.

\section{DISCUSSION}

The problem of sheep pox in sheep in the study areas is very important. This is not only because it is found widely distributed and causes death of lambs and immune suppressed animals, and also affects animals of both sexes and all ages. The sheep were kept under extensive management system on free communal grazing lands. This is believed to have contributed to widespread occurrence of sheep pox infections in the country.

The questionnaire survey showed that many of the respondents knew the clinical signs and effects of sheep pox which they locally called "fentata". The prevalence of sheep pox in the present study (49.5\%) is higher than $22.30 \%$ reported by Senthilkumar et al. ${ }^{[16]}$. This may be because the present study included only those sheep presented to clinics for one or other disease conditions.

The morbidity was found $10.4 \%$ which is in the range of Bhanuprakash's et al. ${ }^{[7]}$ findings. As described by Roy et al. ${ }^{[15]}$ and Babiuk et al. ${ }^{[1]}$, from the physicoclinical observation of sheep infected with sheep pox showed febrile condition (104$\left.108^{\circ} \mathrm{F}\right)$. Full-thickness skin lesions were also detected.

Histopathologically, epidermal changes consisted of acanthosis, parakeratosis and hyperkeratosis but the most important histopathologic skin lesions were massive cellular infiltrate and vasculitis. And as per the world organization for international epizootics, early lesions were characterized by marked perivascular cuffing ${ }^{[12]}$. The cellular infiltrates are macrophages, neutrophils and occasionally eosinophils. As the lesion progresses, numerous macrophages, lymphocytes and plasma cells are found infiltrated. Changes in other organs are similar, with a predominant cellular infiltration and vasculitis. Lesions in the upper respiratory tract are characterized by ulceration ${ }^{[11]}$.

\section{REFERENCES}

1. Babiuk ST Bowden R Parkyn G Dalman B Hoa DM Long NT Vu PP Bieu X do Copps J and Boyle DB (2009). Yemen and Vietnam capripoxviruses demonstrate a distinct host preference for goats compared with sheep. $J$. Gen. Virol. 90(1): 105-114.

2. Balinsky CA Delhon G Afonso CL Risatti GR Borca MV French RA Tulman ER Geary SJ and 
Rock DL (2007). Sheep pox virus kelch-like gene SPPV-019 affects virus virulence. J. Gen. Virol. 81(20): 11392-11401.

3. Balinsky CA Delhon G Simoliga G Prarat M French RA Geary SJ Rock DL and Rodriguez LL (2008). Rapid preclinical detection of Sheep pox virus by Real -Time PCR Assay. J. Clin. Microbiol. 46(2): 438-442.

4. Bancroft JD and Harry CC (1994). Manual of histological techniques and their diagnostic application. $2^{\text {nd }}$ eds. Longman Singapore publisher, Singapore.pp.1-134.

5. Beard PM Sugar S Bazarragchaa E Gerelmaa U Tserendorj S and Tuppurainen E (2009). A description of two outbreaks of Capri poxvirus disease in Mongolia. Vet. Microbiol. 142(3-4): 427-431.

6. Bhanuprakash V Indrani BK Hosamani $M$ and Singh RK (2006). The current status of sheep pox disease. Comp. Immunol., Microbial. Inf. Dis. 29(1): 27-60.

7. Bhanuprakash V Moorthy ARS Krishnapa G Sirinivasa GRN and Indrani BK (2005). An epidemiological study of sheep pox infection in Karanataka State, India. Rve. sci. tech. int. Epiz. 24(3): 909-920.

8. Garner MG Swarkar SD Brett EK Edwards JR Kulkami VB Boyle DB and Singh SN (2000). The extent and impact of sheep pox and goat pox in the state of Maharashtra, India. Trop, Anim. Health Prod. 32(4): 205-223.

9. Mangana O Kottaridi C and Nomikou K (2008). The epidemiology of sheep pox in Greece from 1987 to 2007. Rev. Scient. Tech. 27(3): 899-905.
10. MORAD (2010). Sheep pox diseases out breaks report. Ministry of Agriculture and Rural Development (MORAD), Addis Ababa, Ethiopia.

11. OIE (2004). Sheep pox and goat pox. In: Manual of Diagnostic Tests and Vaccines for Terrestrial Animals, $5^{\text {th }}$ ed. World Organization for Animal Health, Paris, France.

12. OIE (2008). Sheep and goat pox. In: Terrestrial Animal Health Code. World Organization for Animal Health, Paris, France.

13. Ozmen $O$ Kale $M$ Haligur $M$ and Yavru $S$ (2009). Pathological, serological, and virological findings in sheep infected simultaneously with Bluetongue, Peste-des-petits-ruminants, and Sheep pox viruses. Trop. Anim. Health Prod. 41(6): 951-958.

14. Rao TV and Bandyopadhyay SK (2000). A comprehensive review of goat pox and sheep pox and their diagnosis. Anim. Health Res. Rev. 1(2): 127-136.

15. Roy P Purushothaman V Sreekumar C Tamizharasan S and Chandramohan A (2008). Sheep pox disease outbreaks in Madras Red and Mechery breeds of indigenous sheep in Tamilnadu, Res. Vet. scien.85: 617-621.

16. Senthilkumar V Thirunavukkarasu $M$ and Kathiravan G (2006). Survival time in sheep affected by sheep pox and enterotoxaemia. $J$. Anim. Vet. Adv., 5(8): 647-650.

17. Woldemeskel M and Ashenafi H (2003). Study on skin diseases in sheep from northern Ethiopia. Dtsch Tierarztl Wochenschr. 110(1): 20-22. 